\title{
The 'person-in-between' role of young graduates at INGOs in Vietnam
}

\author{
Thi Quynh Lan Mai \\ lanmtq@vnu.edu.vn \\ Vietnam National University Hanoi \\ orcid.org/0000-0002-1508-330X
}

\begin{abstract}
In Vietnam today one of the consequences of globalisation has been a proliferation of international non-government organisations (INGOs). These are intercultural work environments where individuals must seek to understand the culture of others and try to share and find common ground as they strive to fulfil the goals of the organisations. These individuals need high levels of intercultural competence, particularly cultural mediation, important for the role of cultural intermediaries. Drawing on theories of cultural mediation and cultural intermediaries, this research explores the intersection of different cultural worlds in the context of development projects at INGOs in Vietnam. The new graduates in the study reflected on their resources and skills to adapt development models to the local context, thus demonstrating important employability skills. This was particularly challenging given that in organisations such as universities, where the culture was described as rigidly hierarchical, skill training was restricted to following procedures to execute a particular task. However, in organisations like INGOs with high degrees of employee autonomy, decision making is left to the discretion of staff who are required to demonstrate their own means of developing the skills. Based on the findings of the qualitative research into young Vietnamese graduates' experiences of working at INGOs, this paper argues that young graduates play a significant role in disseminating information, and at the same time promoting mutual understanding, forming culturally relativistic attitudes, and demonstrating cross-cultural empathy. They were not just gaining employment, but adding value to an enterprise. Given increasing globalisation, this research makes an interesting argument for the inclusion of cultural literacy as a necessary employability skill for successful engagement in today's world of work.
\end{abstract}

Keywords: graduate's employability, INGOs, cultural mediation, cultural intermediary, intercultural competence

\section{Introduction}

Over the last decade higher education has changed radically in responding to the demands of social, economic and political changes (Bennett, Dunne, \& Carré, 2000). In the new context, the mission of universities has shifted, and knowledge is no longer considered as singular (Barnett, 2000). The traditional role of universities in producing knowledge has changed to give more focus to the demands of society. Furthermore the development of information technology has resulted in rapid changes to the nature of work; graduates need to achieve attributes that help them not only to do the work corresponding with their disciplines, but also to be able to learn new skills and new knowledge (Bennett et al., 2000; 
Dunne, Bennet, \& Carre, 2000). University to work transition can be a difficult process for both the new graduate and the employer.

In Vietnam, two important surveys on the perspectives of the employers organised by the United Nations Development Programme (UNDP) (2007) and the International Labour Organization (2010), reported that many Vietnamese enterprise owners believed that they had to re-train most of their staff on all levels, regardless of their educational background tertiary or post graduate (UNDP, 2007). There is a need for highly skilled and trained staff to meet the human resource demand for current economic development in Vietnam. However, little attention has been given to the views of new graduates: What do they perceive to be their graduate attributes and how do they believe university prepared them (or failed to prepare them) for work, particularly in their important role in society as change agents?

The social and economic context of Vietnam today is encouraging the emergence of a cosmopolitan workforce, which means the traditional boundaries between nations lose their validity (Beck, 2006). In recent years more and more university graduates in Vietnam are working in multicultural organisations. This is one of the consequences of globalisation which has resulted in a proliferation of international business and international non-government organisations (INGOs) operating in Vietnam. The INGOs, the site for this study, represent the kind of fast changing, multi-disciplinary, multicultural work contexts emerging in Vietnam. These organisations function as an important gateway for Vietnamese graduates into other careers. This paper presents the findings from interviews with young graduates working at INGOs in Vietnam. This is a part of a larger exploratory study that investigates Vietnamese graduates' work experience in multicultural environments of INGOs in Vietnam.

\section{INGOs in Vietnam}

Throughout the world, the mission of non-government organisations (NGOs) is to provide either humanitarian support to emergency spots or to implement development projects. The traditional humanitarian values and principles of NGOs are to help the disadvantaged and people in difficult circumstances, and to assist local people to have a greater say in what activities are carried out, be more involved in such activities, and thus develop a stronger civil society and contribute to the processes of democratisation (Willis, 2011, pp. 108-110). Still, the work of (I)NGOs can be subject to criticism, because ideas are imposed by outsiders (Fernando, 2003), or the projects developed are heavily dependent on external experts (Salemink, 2006). Nonetheless, NGOs have some fundamental features, such as being independent from the direct control of any government; not constituted as a political party; non-profit-making; non-violent and with no links to criminal groups (Willetts, 2009). From an anthropological perspective, Richard (2009) argues that NGOs successfully position themselves as the intermediaries between stakeholders. .

In Vietnam, INGOs operate in a particular socio-political context that distinguishes their work from NGOs in some other countries. The state created the framework of INGO operations but still controls the political space available to them (Ghosh, 2009; Gray, 1999). A government body (VUFO) was established to cooperate with, facilitate and regulate INGOs. INGOs in Vietnam collaborate with ministries, provincial and district authorities and also form partnerships with mass organisations at grass-root levels (such as the Women's Union or the Farmers' Association), to facilitate them to carry out campaigns initiated by the state and to implement thousands of projects and credit programs for poor people (Norlund, 2007, p. 22). As employers, INGOs offer new graduates the opportunity to work in fast-changing, multidisciplinary, intercultural work contexts.

The presence of INGOs in Vietnam can be dated back as early as 1948 when INGOs provided assistance for war affected groups of people (Dang, 2009; Nguyen, 2001). At the end of the war, most INGOs closed offices and foreign staff left (Nguyen, 2001). Following the 1986 social and economic renovation (Doi Moi), Vietnam's relationship with the external world had achieved some major improvements, signalled by the 1994 lifting of the embargo 
on Vietnam, which facilitated possibilities for INGOs wishing to support Vietnam. The number of INGOs increased rapidly in responding to immediate needs, however the government and its agencies lacked sufficient resources to handle them (Dang, 2009; Salemink, 2006). Following this ad hoc provision, INGOs introduced development projects to disadvantaged communities. In these projects, new and modern models effective in other parts of the world, were adapted to fit the local context. For example, the Grameen Bank (Bank for the Poor) in Bangladesh was replicated in Vietnam through Credit-Savings projects by INGOs such as Action Aid, Save the Children UK, and OXFAM, and was then institutionalised by the Vietnamese government into the Vietnam Bank for Social Policies.

Today, INGO programs are active in all 61 provinces and centrally-administered cities of Vietnam, supporting activities from the national level to the hamlet and household level, and at every level in between. By 2014, there were about 300 INGOs with offices operating in Vietnam, covering key areas of need, namely health, education, natural resources, income generation, human services, social development, and natural disaster prevention. The INGO Directory 2007, reported around 2,200 Vietnamese staff working in different INGOs in Vietnam (VUFO-NGO, 2007). VUFO-NGO Resource Centre statistics revealed a good mixture of nations among INGOs operating in Vietnam. Of the INGOs currently operating in Vietnam, 40 per cent come from the US and Canada, 40 per cent from Europe, eight percent from Australia and New Zealand, six per cent from Asia and the remaining six per cent are multi-national or INGOs from other parts of the world (Lovrekovic, 2010). This data confirmed a typical feature of the INGO workplace where a small number of international expatriates often held positions to advise the large number of Vietnamese staff.

It is important to note that in Vietnam there are 54 different ethnic groups living together, most of whom have settled in rural or remote areas in difficult geographical and social conditions. Many of these ethnic groups have their own languages and cultures. Very often, they are the primary targets of development projects. This ethnic diversity of the target groups, together with a similar diversity of the human resources at INGOs, make the work context at INGO projects culturally diverse. Researchers argue that people working in such intercultural contexts need a particular set of intercultural competencies (Byram, 1997; TingToomey \& Kurogi, 1998). Hunter, White and Godbey (2006, p. 283) conceptualised intercultural competence as the ability to identify cultural differences, collaborate across cultures, and effectively participate in both social and business settings in other countries. Byram (1997) and Deardorff (2006) have investigated theoretical and developed models of intercultural competencies, and emphasised the increasing importance of intercultural competence in the contemporary globalised workforce. In Byram's (1997) work, the concept of intercultural competence denotes the attributes a person needs to become interculturally, communicatively competent and to be able to see relationships between different cultures, both internal and external. In a survey conducted by Lloyd and Härtel among 1,200 employees of one organisation in Australia, the relationship between an individual and the team in culturally diverse work teams was significantly improved through three facets of intercultural competence, including cognitive competencies, affective competencies and behavioural competencies (Lloyd \& Härtel, 2010, p. 869). Similarly, the importance of intercultural competence in multicultural teams is reconfirmed in cross-cultural research in several European countries (Reid, 2012). In the Spain component of Reid's research, requirements such as cooperation, collaboration and mediation of the global work contexts are intensified through four stages of intercultural learning, including 'never-ending' learning, 'constant' learning, 'unlearning' and 'relearning' processes (Reid, 2012, p. 159). Gow and McDonald (2000) demonstrated that both employers and academics valued highly essential graduate attributes for the modern workplace; nonetheless intercultural competence has not received much attention. 


\section{Graduate attributes}

In recent decades, universities in many countries have been under considerable pressure to clarify the nature of the education they offer to their students. An extensive body of research has developed to address these new demands, reinterpreting the university's purpose and role, in an effort to explain graduates' potential contribution to society (Barnett, 1990). In 2004, Barrie argued that previous research on higher education systems, processes and graduate outcomes had been predominantly descriptive; that is there had been a lack of a conceptual framework or theoretical underpinning (Barrie, 2004; Bennett et al., 2000). There is little evidence to support assertions that so-called core or transferable skills are necessarily outcomes of all higher education programs, or to underpin the identification of good practice in skill development in higher education or employment settings. The work of Bennett, Dunne and Carré is an exception to the general lack of attention to conceptualisation, and provides a foundation for more research (Bennett et al., 2000). Derived from initiatives by employers and staff in higher education, these authors conceptualise generic skills as the main skills thought to be those associated with 'management of information', and in particular, communication.

It is necessary to highlight that what is emphasised at university by universities, and what is emphasised by employers, is not always the same (Eraut, 2004). A large body of research on employers' perspectives about graduate attributes throughout the United Kingdom (UK), the United States of America (USA), Australia and Europe, demonstrates that employers value high level skills. For example, Yorke and Harvey's (2005) research around the employability of the graduates in the UK demonstrates that in the context of social change and massification of higher education, employers are looking for graduates with generic attributes in addition to degree or program knowledge. Employers value the attributes which assist the graduates to adapt to the workplace, to be flexible in moving between different jobs, and to move 'one's repertoire of knowledge' onward (Yorke \& Harvey, 2005). These desirable attributes are often independent of the degree subject, and consist of interactive attributes, including communication skills, interpersonal skills and team working, as well as personal attributes, including intellect and problem solving, analytic, critical and reflective ability, willingness to learn and continue learning, flexibility and adaptability, risk-taking and self-skills (Harvey cited in Yorke \& Harvey, 2005). Hernández-March, Martín del Peso, and Leguey (2009) state that companies seek graduates who have the ability to work in a team and relate with co-workers, clients, and collaborators - skills that, in many cases, prove to be more important than graduate's technical knowledge.

Bennett et al. (2000) argue that the skills that individual graduates developed are constrained or enabled by work circumstances. In the recent decade, rapid social, economic and political changes have urged higher education to focus on providing graduates with skills that meet the demands of the industry (Bennett et al., 2000; Dunne et al., 2000). Work environments have a significant influence on the skill development of graduates. In organisations where the culture was described as rigidly hierarchical, skill training was restricted to following procedures to execute a particular task. In contrast, in an organisation with higher degrees of employee autonomy, decision making was left to the discretion of staff and they were required to organise their own development of required skills (Bennett et al., 2000). Kalfa and Taksa (2015) criticise the assumption held by some universities that 'graduate attributes' are transferable into students' human capital and, therefore, their employability. These authors argue that skills are socially constructed, acquired and transferred through multiple contexts. Notably, most of the existing research on graduate attributes targets academics and/or employers (e.g. Andrews \& Higson, 2008; Barrie, 2006; Harvey, 2005; Hernández-March et al., 2009), with the listed graduate attributes being expectations of academics and employers. However, little has been written on intercultural competence from the graduates' perspectives. 


\section{The Study}

\section{Context}

INGOs, by the nature of the work they undertake, are an example of an intercultural workplace that requires a high level of intercultural competency. INGOs project staff need to work in between different structures, resources and models, and to develop new models for specific projects. In Vietnam the INGOs and their projects are even embedded in the diverse contexts of Vietnamese culture and society. Since development studies is a new field in Vietnam, social work, a cognate discipline, only began to enroll students in around 2006. Therefore, most Vietnamese staff employed in INGOs have not been educated in development-related concepts, knowledge and skills before starting their jobs. Therefore the challenges of working in an INGO are likely to be intensified, especially in the early stages of employment or a career. This raises questions about how universities and employers can assist new graduates to make the transition from formal education to such a workplace.

This study aimed to explore Vietnamese graduates' experience of the intercultural work setting of INGOs, and what they perceive to be their role(s) in the intercultural workplace of INGOs. This research applied inductive qualitative methods to explore how young Vietnamese university graduates experience their work in the intercultural environments of INGOs. Qualitative research can facilitate an understanding of the informants' perceptions, and focuses upon discovering the nature of phenomena as humanly experienced (Minichiello, Aroni, Timewell, \& Alexander, 1995).

\section{Research method}

The research strategy consisted of two stages. Firstly, the context of the INGO workplace was explored via job advertisements. Twenty two INGO job advertisements for positions such as project assistant, research assistant, internship, project secretary, project officer, and project manager were collected during the period 2009-2013 from the official website of the VUFO-NGO resource centre. These job advertisements were descriptively analysed to check the range and consistency of the requirements of different INGO positions, and the meaning of terms used in describing these positions. An analysis of the job advertisements revealed that the primary requirement in terms of qualifications for all job advertisements was a specific university degree (Medical Doctor, Epidemiology, or Health Policy); or a degree qualification in a relevant subject (rural development/agro-forestry, natural resource management, foreign language, social science, social work, community development). English language skills were compulsory in all job advertisements. Work-related experience was also required, even for intern positions (as a preferred point). In more senior positions and specialised jobs, the number of years of experience required could be from two to five years. This requirement was very challenging for graduates who had just finished a three or four-year university program. The scope of qualifications and duties in the job advertisements set the explicit requirements for staff working at INGOs, and raised questions to be checked and further explored in the interviews with the university teachers, employers and the young graduates.Secondly, based on the primary information of job advertisements, the context and experiences of INGO workplaces were explored via in-depth interviews.

\section{Participants}

Participants included international employers in INGOs, young graduates working at INGOs and university teachers. The employers were recruited via established contacts which had been made during the researcher's 10 years of work experience in INGOs in Vietnam. Many of these contacts had subsequently became key brokers to young new staff at INGOs and were willing to participate in the study. Top managers working at INGOs were selected because they had the strongest impact on the decisions made in the organisation. The graduates in the INGOs were then invited to participate in the study. Following initial contact, a small number of young graduates agreed to be interviewed. The snowballing technique

Lan, M. (2017).The 'person- in- between' role of young graduates at INGOs in Vietnam. Journal of Teaching and Learning for Graduate Employability, 8(1), pp. 137-151. 
was then used to locate other participants. The selection of the university teachers as participants was arranged so as to correspond closely to the types of project work at INGOs, as demonstrated through job advertisements.

The total number of participants was 35 , comprising 19 young graduates (15 females and four males), eight university teachers and eight employers. The participants ranged across different age groups from 20-30 years (all 19 young graduates), 30-40 years (five university teachers), and 40-50 years and above (all employers and three university teachers). The gender mix of the group of young graduates reflected the overwhelming number of female staff at INGOs, which was a result of INGOs' mission to empower women. It is the interviews with the graduates which form the basis of this paper.

\section{Data collection and analysis}

Interviews were conducted after the participants had read the research information and given consent to participate. Each interview lasted from 45 to 60 minutes. All interviews were guided to explore the interviewee's daily tasks, the difficulties in completing the tasks, and personal strategies employed to overcome barriers to task accomplishment.

During the interviews, the graduates talked about their work history (the different positions they had held in the same or in different organisations), how they secured their jobs in the first place; the different problems they encountered at the initial stage of their career; and how they resolved those difficulties.

Analysis of the interviews in this first phase revealed various problems or challenges which the young graduates coped with, rooted in their inexperience, their lack of knowledge and skills, and their lack of high level intercultural communication skills, which an INGO intercultural workplace demanded.

To develop a deeper understanding of the experiences of young graduates, the second phase of interviews was conducted with them from September to November 2012, using an interview protocol based on a 'sense-making interview' strategy developed by Dervin (1992). An additional 14 graduates were interviewed in this phase. One or two weeks before the face-to-face interview with each participant in the field, a pre-interview talk by Skype was conducted. The information of the pre-interview was transcribed and translated and the text analysed to identify potential words, concepts, sentences and themes to explore further in formal interviews. To shed light on how graduates apply their knowledge and skills, and experience, and respond to the workplace at INGOs, the results of the interviews of the graduates were analysed in comparison with the interviews of the teachers and the employers.

In their interviews the young graduates used words such as 'liaise', 'convince', 'negotiate', 'compromise' to relate key aspects of their mediation roles. They used the notions of 'shock', 'confusion', 'anger', 'cultural differences', 'giving feedback', 'boss', and 'doers' to classify issues that demanded attention and action. The common concepts that emerged from the analysis of the interviews with the graduates were 'unawareness of cultural differences', 'inappropriateness of skills', 'shortage of appropriate knowledge', 'trial and error', 'being cautious', 'in-between position', 'advocating' and 'facilitating'. These are reflected in the discussion of the findings below.

\section{Findings}

The following section discusses the findings from the interviews with the young graduates working at INGOs. Their stories (the names have been changed) uncover contradictions between their university study and work requirements at INGOs. Most of them experienced a traditional teacher-focussed teaching approach at their universities. However, the INGOs workplace required graduates to be continuous learners, to have critical mindsets, to possess effective negotiation, communication and interpersonal skills, and particularly to be 
culturally competent. Young graduates' stories exposed their hardship at the beginning of their work at INGOs.

\section{Inappropriate knowledge and skills}

Although their difficulties varied, a common basis to their problems was identified as insufficient preparation for the intercultural work environment. The typical traditional teaching and learning approach at university was clear in Ms Hoa's accounts. Having graduated in 2006, with a major in English language, Ms Hoa was taught by a traditional learning approach where students mostly learned what the teacher instructed, as she explains:

My teachers only asked us to search through internet, but did not explain how to search, how to use the keywords for searching what we were looking for (Ms Hoa, Project Assistant).

Consequently, graduates arrived unable to deal with the requirements of being independent in decision making at work. Graduates also found it hard to apply their university knowledge and skills in strange work contexts. This was clear in the accounts of other participants as well, particularly those who graduated before 2010. As Ms Ba, (graduated in 2009, interviewed in 2012), and Mr Vi, (graduated in 2011, interviewed in 2012), commented:

My background was foreign language. In the early days, when my supervisors asked me to comment [on the content of the draft of the training material], I felt I was not capable to give comments on this content (Ms Ba, Project Assistant).

... when I started my job, I had to learn more. It was very difficult to use the university knowledge then (Mr Vi, Project Assistant).

Those young graduates also had to learn new knowledge and skills by doing or observing, like Mr Xuan, (graduated in 2006, interviewed in 2012), and Ms Hoa:

I got a very short orientation. I thought it was not enough for me to become confident in doing the financial management role. I had to learn by doing (Mr Xuan, Project Manager).

I observed others; I practiced giving a presentation at home. If I had to make a presentation to many people, I would practice at home in advance. However, I mainly learnt through observing others' presentations. The senior staff also advised how to make a presentation (Ms Hoa, Project Associate).

Communication technology had developed dramatically within a short time and had changed the way many students studied. In 2006, when Ms Hoa was at university, the internet service was not so available that she had to rely on her teacher for internet searching skills.

However, some more recent graduates enjoyed more advanced learner-focussed teaching approaches than their senior alumni. For example, Ms Dao (graduated in 2011, interviewed in 2012), confirmed that she used the internet daily in her study. Indeed, she conducted an independent study together with a Swedish exchange student to enlighten the local farmers in a village about the harmfulness of pesticide. Although she did not study agriculture at her university, Ms Dao searched through the internet for the relevant knowledge about pesticide to teach the farmers.

I only knew the basic concept that pesticide could have bad impact upon the water source and polluted the air which was inhaled by the human being. ..... When I saw that the local people did not know some knowledge, I googled to 
find the suitable knowledge for the local people (Ms Dao, interpreter/ Project Assistant).

The university experiences of those participants who graduated from 2010 onwards also showed a trend of teachers applying new teaching approaches to develop students' creativity. Ms Dao studied with a culturally diverse team of teachers, coming from abroad. They used teaching approaches different from the traditional Vietnamese methods. Her teachers expanded their lectures beyond the textbook contents, asking their students to explore new knowledge:

I had to read a thick English book on micro economics, because the teachers taught knowledge beyond the textbook. This helped me to be independent, to have critical thinking skill and to know how to raise questions (Ms Dao, interpreter/Project Assistant).

\title{
'In-between' position: Language and communication
}

Despite these more modern teaching approaches and their good command of English language at university, most of the participants (both female and male) had difficulties in interpreting and translating English at their first jobs. Most of them started their careers in intern positions or positions such as interpreters or project assistants. Translation in the context of INGOs is not a simple transfer of meaning between people who do not speak the same language. Young graduates need to mediate between international experts and local people whose cultural dispositions, practices and customs are not the same. The concept of cultural mediation means a process designed to manage and resolve conflicts between two or more parties (McKay, 2008). It is a facilitated negotiation process, in which both parties can identify their interests and needs, raise their ideas and opinions, and propose solutions for problems. The graduates in the current research even had to accustom themselves to the cultural practices of the international experts first to guide the parties through the process without determining the outcome (McKay, 2008, np). As in the words of Ms Mau, (graduated in 2006, interviewed in 2011), and Ms Dao:

\begin{abstract}
... When the international consultants contacted Vietnamese people, I was their assistant. I was like the person in between. This meant that sometimes there were some expressions that were quite at odds with the culture of Vietnam ... I had to find out whether the international consultant had said inappropriate thing. If that I had to find ways to explain, as a kind of trouble shooting (Ms Mau, Project Assistant).
\end{abstract}

As the interpreter, I was like a person in-between to solve the problem. In many instances, I had to please both sides. It was really difficult (Ms Dao, the interpreter).

Bochner argues that cultural mediation is essential in work that requires agreement between people from different cultures or different ethnic groups (Bochner, 1981). Cultural mediators do more than disseminating information between two or more parties; they promote mutual understanding, form culturally relativistic attitudes, produce cross-cultural empathy, spread international (or inter-cultural) goodwill and reconcile disparate cultural practices (Bochner, 1981). Bochner's view of 'cultural mediation' is expanded by Cronin's (2004) position that the mediating practitioners' role should be viewed as a negotiation between multiple regimes of mediation (p. 349).

In the current research, graduates compared and contrasted cultural differences in the communication process between the Vietnamese and international consultants, and developed the cultural literacy that enabled them to be successful cultural mediators. They recounted profound differences in people's ways of thinking, analysing and understanding

Lan, M. (2017).The 'person- in- between' role of young graduates at INGOs in Vietnam. Journal of Teaching and Learning for Graduate Employability, 8(1), pp. 137-151. 
activities and practices due to their cultural diversity. This often resulted in misunderstanding and confusion. For example Ms Mau experienced stressful miscommunication between her and the international boss due to culturally different ways of giving feedback:

When you have a problem, the international experts give very direct feedback. At first I was unfamiliar with that way, I felt it tough..... The foreigners are very direct. Initially I felt unfamiliar with this; there are instances when I felt very stressful, the work is very stressful (Ms Mau, Project Assistant).

Another girl, Ms Dang, (graduated in 2011, interviewed in 2012), was unsure of what to say when meeting a big boss:

Once, when a big boss came, we did not dare to be open in communication. It was not because of language barrier. It might be because he was a very big boss so we were worried that we might say something unnecessary [that might annoy him] (Ms Dang, Project Assistant).

\section{Culture and cultural intermediaries}

People of the same culture can more easily understand each other because they are familiar with the same system of values. The research of Leach (1976), Triandis (2000), and TingToomey (2012) points to this influence of culture on the communication process. They argue that collectivism and individualism influence intercultural communication processes, and that within each culture, different ethnic groups may display distinctive individualistic and collectivistic value patterns (Ting-toomey, 2012, p.69). It was difficult for the person in the middle to understand the differences in the system of values of other cultures. Those dealing with different ethnic groups had even more challenging tasks. They had to understand the two different cultures, while at the same time ensuring that they enable both sides to work together to come to a new understanding. For example, Ms Vu, (graduated in 2009, interviewed in 2010), experienced the differences between the concepts of planning and scheduling of the project staff and the local community:

My INGO very highly appreciates the completion at deadline, because the progress of this work will lead to the result of the next activity. But sometimes they [local partners] do not see the importance of the proposed timeline, following the objectives. They might not even like doing this first, doing that later [...] sometimes they work by their own way, without complying with the original schedule (Ms Vu, Project Officer).

In their functional role as the link between two or more cultural systems (Bochner, 1981), some young graduates used their own experiences to localise foreign models of intervention and development. They became the cultural intermediary (Bourdieu, 1984). The concept of cultural intermediary was used by Bourdieu (1984) to denote a new type of worker who works between cultural production and cultural consumption. More recently, Negus (2002) stated that while Bourdieu's concept privileges a group of occupations that come in-between creative artists and consumers, there are now many other occupational groupings that are crucial to processes of cultural mediation (p. 503). Edwards (2012) argues that the role of public relations practitioners who formulate and disseminate information designed to influence values and attitudes about social and cultural roles, identities and practices, is a new form of cultural intermediary. The role of public relations practitioners in Edwards' research is similar to Cronin's (2004) conceptualisation of multiple-regimes mediation, and is applicable to explain the mediation role of young graduates in the current research.

For example, Ms Hoa recalled her experience of translating and facilitating a training workshop where the experts introduced medical anthropology to the trainees using case studies from abroad, unfamiliar within Vietnamese culture. Neither the project staff nor the

Lan, M. (2017).The 'person- in- between' role of young graduates at INGOs in Vietnam. Journal of Teaching and Learning for Graduate Employability, 8(1), pp. 137-151. 
trainees fully understood the new method. The learners were concerned that without local case-studies they could hardly disseminate the new method to the local people effectively. Ms Hoa brought these concerns to the trainer.

The biggest gap, for example, was the fact that he [the expert] provided too many examples from Australia; however, the Vietnamese learners wanted to know about the Vietnamese context...I incorporated opinions of all groups into a report and translated into English so that the trainers and the learners could discuss together (Ms Hoa, Project Associate).

Ms Hoa also contributed to the discussion for developing local case studies by describing her observations of medical practices at her home village. She had formed the links between people of different cultures - the experts, the Vietnamese medical workers, and herself. She also skilfully crafted the medical anthropology method into one that suited the Vietnamese local context. At this level, Ms Hoa had moved from cultural mediator to cultural intermediary (Bourdieu, 1984). Like Ms Hoa, other informants including Mr Ta, Mr Xuan and Ms Nguyen demonstrated the role of cultural intermediaries in their accounts. They mostly gained the necessary work knowledge and skills before performing as cultural intermediaries by adding relevant values to original (imported) project models or ideas.

$\mathrm{Mr}$ Ta got a job as a field project officer position on child rights. In order to promote a better future for female teenagers in mountainous regions, his project set a goal to reduce the early marriage rate among young girls. Although the legal marriage age in Vietnam is 20 years for men and 18 for women according to marriage and family law, many ethnic groups maintain their customs of early marriage for young girls which could possibly lead to health risks for very young mothers. While translating and facilitating training on the harmfulness of early marriage, and the benefits of delayed marriage, $\mathrm{Mr}$ Ta tried to encourage learners to inform the consultant about their opinions and their views.

I assisted in creating a more open environment among the learners. If the learners kept silent when the consultants raised questions, I warmed them up, or clarified the questions so that the learners understood the questions and could answer. The most important thing was the learners' answers ( $\mathrm{Mr} \mathrm{Ta}$, Project Officer).

While clarifying the questions, Mr Ta contributed his understandings of the negative social and health impacts of early marriage among young girls in order to enlighten the local people. In doing that, he was involved in changing the behaviour pattern of the local community and raising their awareness of the benefits of delayed marriage.

The case of Mr Xuan is another example of a cultural intermediary transforming a traditional practice. As the manager of the program for child nutrition promotion, Mr Xuan and his project team crafted a social franchise model to tailor the user-paid counselling services according to the clients' needs. This was a very different approach from the traditional generic free nutrition counselling service being applied at most of state health clinics. $\mathrm{Mr}$ Xuan reasoned that the fee-paying service would make users more concerned about service quality. This model was new in Vietnam so his project had to start up from the very beginning, from developing a brand name to training the providers:

I understood that this model developed from the demand for improving child nutrition, particularly to reduce malnutrition and improve child growth ratios. To conduct social franchise work, the model needed to have a very unique brand name (Mr Xuan, Program Manager).

His program trained the nutrition providers with updated knowledge on child nutrition to bring their services up to international standards. Mr Xuan's functional mediation (Bochner, 1981) 
led to his engagement as an intermediary, in changing the health policy towards a 'socialising', sustainable, high quality, fee-paying and individually-tailored model.

The case of Ms Nguyen, (graduated in 2004, interviewed in 2010), was an exceptional example of a cultural intermediary who applied her accumulated experiences to continuously craft new models. Ms Nguyen got her first job as a project assistant at an education project for ethnic minority children in a mountainous district. She energetically negotiated her hybrid model which combined developing a participatory method with the existing activities of the school parents' association. She equated the involvement of the parents' association in the local school activities with a participatory approach. Her argument was that this type of parents' association of school children had worked effectively in Vietnam for a long time, so it was necessary to take this fact into account when applying the participatory method, as she explained:

The participation method required that parents needed to be involved in the school process. ...In theory, the child participation approach had its own principles; however, which activities should be done to ensure those principles?... We should not create completely new activities (Ms Nguyen, Project Officer).

Her model continued to prove its effectiveness in her second job where Ms Nguyen worked with her team to develop a new model of user-friendly libraries at primary schools in ethnic minority areas. Not just disseminating information, Ms Nguyen negotiated her ideas and her lessons drawn from her previous projects, to influence the model. Although some researchers claim that development might end up imposing alien models upon indigenous populations (Fernando, 2003; Mosse \& Lewis, 2006; Salemink, 2006), Mr Xuan and Ms Nguyen's successes in adapting new models into local contexts by using their abilities to analyse, critically evaluate and solve problems has proved their capabilities to mediate between the ideas of international experts and the practices and traditions of local people in their project sites.

\section{Discussion}

The stories of the young graduates have illustrated the role of cultural mediator and cultural intermediaries in INGOs contexts. In many situations there were significant cultural differences, manifested in super/ subordinate relations, imposition of foreign ideas and models, interpreting rules and other documents and giving culturally sensitive feedback. In these situations there is the potential for conflict to arise from the cultural differences within intercultural interactions. Such problems mainly occur during the communication process in which people of different cultures need to exchange ideas to come to agreement (Tingtoomey \& Kurogi, 1998). In the current research, the graduates became interculturally competent through their observation of the practices of international consultants and local people, or drawing lessons out of miscommunication situations. Young graduates needed to mediate between different cultural norms, practices and customs of people from different cultures (Bochner, 1981, Ting-Toomey, 2012). In their cultural mediation role, they did more than disseminating information rather promoting mutual understanding, and reconciling disparate cultural practices.

It is noticeable that the cultural intermediary role was not explicitly stated by young graduate in their accounts. As it is not a formally recognised aspect of their work, young graduates had no language with which to discuss or name this aspect of their work, making it all more challenging for them. Cultural intermediary roles were not usually performed in the very first job after graduation. As young graduates strategically acquired 'on-the-job' work knowledge and skills, they appeared to capitalise on these resources and moved on to other positions where they could apply their newly acquired knowledge and skills. 


\section{Conclusion}

This research contributes to the theory of cultural mediation and cultural intermediaries by its insights into the way young graduates negotiated the local norms, customs and practices into the development models applied in their contexts. This research also highlights the importance of the intercultural dimension of the 'global' workplace. As cultural mediators and cultural intermediaries, young graduates disseminate information, and at the same time promote mutual understanding, form culturally relativistic attitudes and develop cross-cultural empathy. They were not just gaining employment, but adding value to an enterprise, in this case the effectiveness of INGOs in Vietnam.

Given increasing globalisation, this research makes an interesting case for the inclusion of cultural literacy as a necessary employability skill for successful engagement in today's world of work. The young people cited in the study were clearly able to make a difference for Vietnamese communities, bringing with them, both the technical skills and knowledge gained at university, and the abilities to analyse, critically evaluate and problem solve. The way the new graduates reflected on their resources to adapt the development models to the local context demonstrated the capabilities which enhanced their employability as graduates. The findings from this research also have an implication for the wider Asian Region in the globalisation era. As an ethnically diverse region, Asian Region cooperation promises plenty of opportunities for collaboration across cultures. Universities should focus on developing intercultural competence for graduates to make them competent entering this employment market context.

Since this research focuses on young graduates working at INGOs in Vietnam whose projects are targeted specifically at vulnerable, local communities, it is difficult to generalise from the experience of the young graduates in this study. Future research about intercultural competence should be on a much larger scale, exploring other types of workplace in all economic sectors including private and state businesses, all of which increasingly face the challenges of the intercultural interaction.

\section{Acknowledgments}

This research was supported by a PhD Scholarship co-funded by the Ministry of Education and Training of Vietnam and the University of Queensland, Brisbane Australia (Ethics approval number: RHD/8-2010). The author acknowledges thoughtful comments and advice on earlier drafts from the anonymous reviewers. Sincere thanks to the participants who were generous in contributing their time and efforts to the interviews. 


\section{References}

Andrews, J., \& Higson, H. (2008). Graduate employability, 'soft skills' versus 'hard' business knowledge: A European study. Higher Education in Europe, 33(4), 411-422. http://dx.doi.org/10.1080/03797720802522627

Barnett, R. (2000). University knowledge in an age of super complexity. Higher Education, 40(4), 409-422. doi:10.1023/A:1004159513741

Barrie, S. (2006). Understanding what we mean by the generic attributes of graduates. Higher Education, 51(2), 215-241. doi:10.1007/s10734-004-6384-7

Bennett, N., Dunne, E., \& Carré, C. (2000). Skills development in higher education and employment. Taylor \& Francis: Florence.

Bochner, S. (1981). The social psychology of cultural mediation. In S. Bochner (Ed.), The mediating person: Bridges between cultures (pp. 6-36). Cambridge: G.K. Hall.

Bourdieu, P. (1984). Distinction: A social critique of the judgement of taste. Mass.: Harvard University Press.

Bourdieu, P. (1990). The logic of practice. (Trans. by R. Nice.) Stanford: Stanford University Press.

Byram, M. (1997). Teaching and assessing intercultural communicative competence. Philadelphia: Multilingual Matters.

Cronin, A. M. (2004). Regimes of mediation: Advertising practitioners as cultural intermediaries? Consumption, Markets \& Culture, 7(4), 349-369. doi: $10.1080 / 1025386042000316315$

Dang, L.H. (2009). Non-governmental organizations (NGOs) and development: An illustration of foreign NGOs in Vietnam (Doctoral dissertation, Ohio University).

Deardorff, D. (2006). The Identification and assessment of intercultural competence as a student outcome of internationalisation at institutions of higher education in the United States. Journal of Studies in International Education, 10, 241-266.

Dervin, B. (1992). From the mind's eye of the user: The sense-making qualitativequantitative methodology. In J. D. Glazier \& R. R. Powell (Eds.), Qualitative research in information management (pp. 61-84). Libraries Unlimited: Englewood.

Dunne, E., Bennet, N., \& Carre, C. (2000). Skill development in higher education and employment. In F. Coffield (Ed.), Differing visions of a learning society, Research findings, 1 (pp. 105-13). http://hdl.voced.edu.au/10707/157732.

Edwards, L. (2012). Exploring the role of public relations as a cultural intermediary occupation. Cultural Sociology, 6(4), 438-454. doi:10.1177/1749975512445428

Eraut, M. (2004). Transfer of knowledge between education and workplace settings. In $\mathrm{H}$. Rainbird, A. Fuller \& A. Munro (Eds.), Workplace learning in context (pp. 201-221). London; New York: Routledge.

Fernando, J. L. (2003). NGOs and production of indigenous knowledge under the condition of postmodernity. The ANNALS of the American Academy of Political and Social Science, 590(1), 54-72. doi: 10.1177/0002716203258374

Ghosh, S. (2009). NGOs as political institutions. Journal of Asian and African Studies, 44(5), 475-495. doi: 10.1177/0021909609340063

Gow, K., \& McDonald, P. (2000). Attributes required of graduates for the future workplace. Journal of Vocational Education \& Training, 52(3), 373-396.

http://dx.doi.org/10.1080/13636820000200126

Gray, M. L. (1999). Creating civil society? The emergence of NGOs in Vietnam. Development and Change, 30(4), 693-713. doi:10.1111/1467-7660.00134 
Harvey, L. (2005). Embedding and integrating employability. New Directions for Institutional Research, 128, 13-26. doi:10.1002/ir.160

Hernández-March, J., Martín del Peso, M., \& Leguey, S. (2009). Graduates' skills and higher education: The employers' perspective. Tertiary Education and Management, 15(1), 116. http://dx.doi.org/10.1080/13583880802699978

Hunter, B., White, G. P., \& Godbey, G. C. (2006). What does it mean to be globally competent? Journal of Studies in International Education, 10(3), 267-285. http://dx.doi.org/10.1177/1028315306286930

Kalfa, S., \& Taksa, L. (2015). Cultural capital in business higher education: Reconsidering the graduate attributes movement and the focus on employability. Studies in Higher Education, 40(4), 580-595. http://dx.doi.org/10.1080/03075079.2013.842210

Leach, E. (1976). Culture and communication: The logic by which symbols are connected. An introduction to the use of structuralist analysis in social anthropology. Cambridge University Press.

Lloyd, S., \& Härtel, C. (2010). Intercultural competencies for culturally diverse work teams. Journal of Managerial Psychology, 25(8), 845-875. doi: 10.1108/02683941011089125

Lovrekovic, M. (2010). Assessment of International Development NGO Activities in Vietnam. Paper presented at The 2010 Conference on Humanitarian and Development Assistance to the Democratic People's Republic of Korea, 15-17 November, Seoul, Korea.

McKay, J. (2008). "Mediation". In V. N. Parrillo (Ed.), Encyclopedia of social problems. Calif.: Thousand Oaks.

Minichiello, V., Aroni, R., Timewell, E., \& Alexander, L. (1995). In-depth interviewing: Principles, techniques, analysis (2nd ed.). Melbourne: Longman.

Mosse, D., \& Lewis, D. (2006). Theoretical approaches to brokerage and translation in development. In D. Lewis \& D. Mosse (Eds.), Development brokers and translators: The ethnography of aid and agencies (pp. 1-26). Bloomfield: Kumarian Press.

Negus, K. (1992). Producing pop: Culture and conflict in the popular music industry. London: E. Arnold.

Negus, K. (2002). The work of cultural intermediaries and the enduring distance between production and consumption. Cultural Studies, 16(4), 501-515. doi: 10.1080/09502380210139089

Nguyen Kim Ha (2001). Lessons learned from a decade of experience: A strategic analysis of INGO methods and activities in Vietnam 1990-1999. VUFO-NGO Resource Center. Hanoi: VUFO-NGO Resource Centre Vietnam.

Norlund, I. (2007). Filling the gap: The emerging civil society in Viet Nam. Hanoi: UNDP.

Reid, A. (2012). Intercultural Competence in a Foreign Language Classroom: GRIN Verlag.

Richard, A. M. (2009). Mediating dilemmas: Local NGOs and rural development in neoliberal Mexico. Political and Legal Anthropology Review, 32(2), 166-194. doi: 10.1111/j.15552934.2009.01040.x

Salemink, O. (2006). Translating, interpreting, and practicing civil society in Vietnam: A tale of calculated misunderstandings. In D. Lewis \& D. Mosse (Eds.), Development brokers and translators: The ethnography of aid and agencies (pp. 101-126). Bloomfield: Kumarian Press.

Ting-Toomey, S., \& Kurogi, A. (1998). Facework competence in intercultural conflict: an updated face-negotiation theory. International Journal of Intercultural Relations, 22(2), 187-225. doi: 10.1016/S0147-1767(98)00004-2

Ting-Toomey, S. (2012). Communicating across cultures. New York: Guilford Press.

Triandis, H. C. (2000), Culture and Conflict. International Journal of Psychology, 35(2), 145152. doi:10.1080/002075900399448

Lan, M. (2017).The 'person- in- between' role of young graduates at INGOs in Vietnam. Journal of Teaching and Learning for Graduate Employability, 8(1), pp. 137-151. 
VUFO-NGO resource center (2007). Vietnam INGO directory 2007. Hanoi: VUFO-NGO resource center Viet Nam.

Willetts, P. (2009). What is a non-governmental organization? Online resource.

http://www.staff.city.ac.uk/p.willetts/CS-NTWKS/NGO-ART.HTM\#Part10. Accessed on 29 March 2013.

Willis, K. (2011). Theories and practices of development [2nd ed.]. New York: Routledge.

Yorke, M., \& Harvey, L. (2005). Graduate attributes and their development. In R. A. Voorhees \& L. Harvey (Eds.), Workforce development and higher education: A strategic role for institutional research (pp. 41-58). San Francisco: Jossey-Bass. 